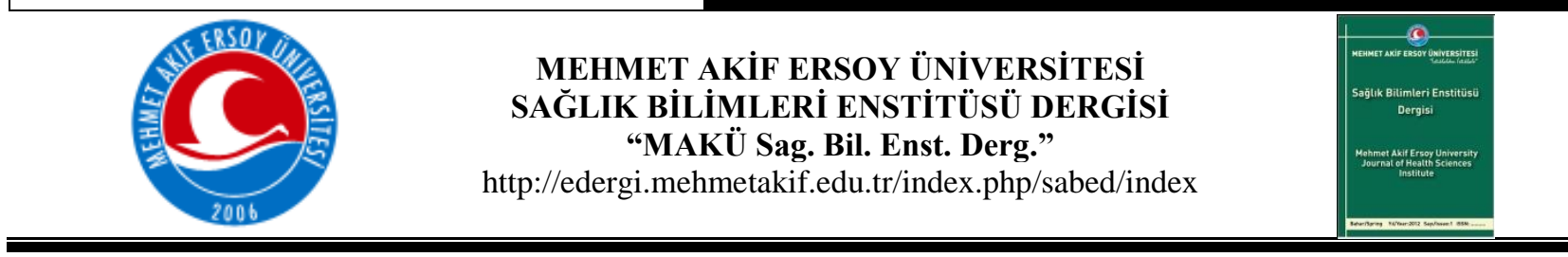

\title{
Memeli Hücrelerinde Otofajinin Moleküler Mekanizması
}

\author{
Molecular Mechanism of Autophagy in Mammalian Cells
}

\author{
Yasemin Sahin, Dilara Akcora Yıldız \\ Biyoloji Bölümü, Fen-Edebiyat fakültesi, Mehmet Akif Ersoy Üniversitesi, Burdur, Turkey
}

\begin{abstract}
Macroautophagy (henceforth autophagy), an evolutionarily conserved mechanism from yeast to human, protects cells from starvation and related stresses and reduces macro-molecules to building blocks that can be used to supply energy. Autophagy is an intracellular degradation pathway that traffics bulk cytoplasm, organelles (e.g., mitochondria and peroxisomes), aggregate-prone proteins, and infectious agents to lysosomes via double-membrane vesicles called autophagosomes. Essential roles for autophagy in health and disease have been displayed by studies of mammalian systems. Research on animal models of both neurodegenerative and infectious diseases before the clinical trial showed that autophagy upregulation plays an essential role in degradation of aggregate-prone intracytoplasmic proteins causing various neurodegenerative disorders, including forms of dementia (caused by tau), Parkinson's disease ( $\alpha$-synuclein), and Huntington's disease (mutant huntingtin) and in protection against certain infectious diseases caused by pathogenic agents, such as Salmonella typhi and Mycobacterium tuberculosis. Autophagy, emphasised the need to maintain the continuity of mouse hematopoietic stem cells (HSCs), switches HSCs from a normal to a pre-leukemic state when the function of autophagy is impaired. While the reduction in autophagic activity due to mutations or decreased expression of critical autophagic regulators supports the development of pre-leukaemia, reactivation of this mechanism with agents used in the treatment leads to the recurrence of the disease. Autophagy activation level plays an essential role in cancer progression, obesity and metabolic diseases due to its role in anabolic and catabolic processes. The number of studies on the molecular mechanisms of autophagy in health and the pathogenesis of various diseases is increasing day by day. In this review, it is aimed to provide an overview and give information about autophagy and its molecular mechanism in mammalian cells.
\end{abstract}

Key words: Autophagy, mammary cells, molecular mechanism, ATG

Yazışma Adresi: Dilara AKCORA YILDIZ, Mehmet Akif Ersoy Üniversitesi, Fen Edebiyat Fakültesi,Biyoloji Bölümü, 15030/Burdur, Turkey

E-mail: dilaraakcora@mehmetakif.edu.tr,

Tel: 00905330397810

Enst. Derg. 5(2): 205-218.

Öz: Mayadan insana kadar evrimsel olarak korunmuş bir mekanizma olan makrootofaji (bundan sonra otofaji), hücreleri açlıktan ve buna bağlı streslerden korumakta ve makromolekülleri enerji sağlamak için kullanılabilecek olan yap1 taşlarına indirgemektedir. Otofaji, bir parça sitoplazma yığınını, organelleri (örneğin mitokondri ve peroksizomlar), agregat oluşturmaya eğilim gösteren proteinleri ve enfeksiyöz ajanları otofagozomlar olarak adlandırılan çift-membranlı veziküllerle lizozomlara taşıyan hücre içi parçalanma yoludur. Memeli sistemi üzerine yapılan çalışmalar, sağlık ve hastalıkta otofajinin diğer önemli rollerini göstermiştir. Klinik öncesi nörodejeneratif hastalıklarla ilgili hayvan modellerinde yapılan araştırmalar, otofaji aktivasyonunun Parkinson hastalığ 1 ve Huntington hastalığı gibi çeşitli nörodejeneratif hastalıklara neden olan agregata eğilimli intrasitoplazmik proteinlerin parçalanmasında önemli bir rol oynadığını göstermiştir. İlaveten, otofaji aktivasyonunun Salmonella typhi ve Mycobacterium tuberculosis gibi patojenik ajanlardan kaynaklanan belli bulaşıcı hastalıklara karşı korunmada önemli bir etken olduğu rapor edilmiştir. Fare hematopoietik kök hücrelerin (HSCs) devamlılığının sürdürülmesinde gerekliliği vurgulanan otofaji, fonksiyonelliği bozulduğunda HSC'leri normalden pre-lökemik bir duruma geçirmektedir. Otofajinin tedavide kullanılan ajanlarla yeniden etkinleştirilmesi ise hastalığın nüksetmesine yol açmaktadır. Otofaji aktivasyon düzeyi, kanser progresyonu ile anabolik ve katabolik işlemlerde üstlendiği rollerden dolayı obezite ve metabolik hastalıklarda önemli rol oynamaktadır. Otofajinin sağlıkta ve çeşitli hastalıkların patogenezindeki moleküler mekanizmalarına ilişkin çalışmaların sayısı gün geçtikçe artmaktadır. Bu derlemede, memeli hücrelerinde gerçekleşen otofaji ve moleküler mekanizması hakkında genel bir bakış sunulması ve bilgi verilmesi amaçlanmıştır.

Anahtar sözcükler: Otofaji, memeli hücresi, moleküler mekanizma, ATG

Geliş Tarihi: 17.11.2017 Kabul Tarihi: 04.12.2017 


\section{Giriş}

Hücre homeostazı, biyosentezin ve yıkımın dengelenmesi ile sağlanmaktadır. Hücresel ve doku homeostazını düzenlemek üzere işlev gören otofaji, strese karşı yanıt veya farklılaşma gibi çeşitli hücresel süreçlerde önemli rol oynayan, hücrelerin protein agregatları, hasar görmüş organelleri ve istilacı patojenleri parçalayarak geri dönüşümünü sağlayan evrimsel olarak korunmuş bir süreçtir (Liu, 2017). Ökaryotik hücrelerde lizozom (veya maya analoğu ve bitki vakuolü), sahip olduğu asit hidrolaz enzimlerinden dolayı parçalanma olayının gerçekleştiği hedef organeldir. Hücresel adaptasyon veya hayatta kalmak için önemli olan otofaji, besin yoksunluğu, radyasyon, metabolik stres, endoplazmik retikulum (ER) stresi ve kemoterapötik ajanlar da dâhil olmak üzere farklı stres koşulları altında uyarılabilmektedir (Yoshida, 2017). Otofaji besin yoksunluğu gibi olumsuz koşullara adaptif bir yanıt olarak, lizozomlar vasıtasıyla oldukça sıkı kontrol altında olan bir kendini yeme (self-eating) sürecine aracılık eder. Otofagozom adı verilen çift membranlı veziküller, uzun ömürlü proteinleri, hasar görmüş organeller ile istilacı patojenleri içine alarak bu kargoları lizozomlara nakleder (He ve Klionsky, 2009). Lizozomlarda ise bu kargolar, asit hidrolaz enzimleri tarafindan parçalanmaktadır. Mikrootofaji, lizozom veya endozom zarının içe doğru çıkıntı yaparak subtratın içeri alınması ve lizozomal proteazlarla parçalanmasını ifade etmektedir. Şaperon aracılı otofaji ise hem otofaji hem de mikrootofajiden farklıdır; çünkü kargo bir zar ile sınırlandırılmış vezikül içinde tutulmaz. Bunun yerine, şaperon-aracılı otofaji tarafından hedeflenen proteinler, sitozolik $70 \mathrm{kDa} 1 \mathrm{~s} 1$ şoku şaperon proteini (HSC70) tarafından tanınan KFERQ-benzeri pentapeptid motifi içermektedir. HSC70, lizozomal ilişkili zar proteini 2A reseptör (LAMP2A) aracılığıyla bu hedeflerin lizozomal zardan lizozom lümenine geçişini kolaylaştırır (Kaur ve Debnath, 2015).

\section{Otofajiye Genel Bakış}

Diğer hücre ölümlerine kıyasla otofajinin en belirgin özelliği, biyomoleküller, organeller ve mikropların da dâhil olduğu hücredeki neredeyse her şeyi parçalayabilme yeteneğidir (Mizushima ve Komatsu, 2011). Otofaji, seçici ya da seçici olmayan olarak kategorize edilebilir. Seçici ve seçici olmayan otofaji uyarıcı sinyalleri, taşıdıkları madde türü, kargonun alıkonma mekanizması bakımından birbirlerinden farklılık göstermektedir (Yin ve ark. 2016). Seçici olmayan otofaji, besin yoksunluğu ya da metabolik bozulmalar tarafından indüklenir. Sitoplazmanın herhangi bir kısmının bu degradasyon yolağı üzerinden geri dönüşümü sağlandığı düşünülmektedir. Seçici otofaji ise hasarlı ve/veya fazla olan yapıların 
hücreler için toksik olmadan önce yok edilmesini kolaylaştırır (Johansen ve Lamark 2011). Ayrıca, seçici otofaji tipik olarak hedef üzerinde bir ligand ve seçici otofaji reseptörlerinin en az bir iskele proteini ile birlikte bulunması gibi degredasyon ipuçlarının varlı̆̆ı ile karakterizedir (Kaur ve Debnath, 2015, Yin ve ark. 2016). Otofaji ile organellerin seçici olarak parçalanması, organizmalarda hücresel homostazının sürekliliği için hayati önem taşır. Hasar gören organellerin temizlenmesini ve biyoenerji için organel bileşenlerin tekrar kullanılmasını sağlayan mitofaj, peksofaj, lizofaj, retikulofaj (ER-faj), nükleofaj, klorofaj mekanizmaları tanımlanmıştır. $\mathrm{Bu}$ organele özgü otofaji mekanizmalarının etkinliği sonucunda mitokondri, peroksizom, lizozom, ER, kloroplast ve çekirdek ortamdan kaldırılabilmektedir. Organel temizlenmesindeki kusurlar hücrelerin sağlığına zarar vermekte dolayısıyla, kansere, nörodejenerasyona ve inflamasyona yol açabilmektedir (Anding ve Baehrecke, 2017).

Otofajinin özellikle besin yoksunluğu, radyasyon, metabolik stres, ER stresi ve kemoterapötik maddeler ile uyarıldığı vurgulanmaktadır (Yoshida, 2017). Ancak, uygun büyüme koşullarında bile bazal otofaji ile sitoplazmik içeriklerin sürekli deviri normal hücre fizyolojisi için oldukça önemlidir.

Yeni çalışmalar, otofajinin hücrenin gelişmi sırasında da vazgeçilmez olduğunu göstermektedir. Örneğin, otofaji mayada spor oluşumuna katılırken, Caenorhabditis elegans (C. Elegans) somatik hücrelerinde $\mathrm{P}$ granüllerinin oluşumu ve parçalanması için gereklidir. Ayrıca, yine C. elegans'da oosit döllenmesinden sonra otofajinin maternal mitokondrinin ortadan kaldırılmasında rol aldığı rapor edilmişstir (Al Rawi ve ark. 2011, Sato ve Sato, 2011). Drosophila melanogaster'de ise otofaji mutantları larva letalitesini ve metamorfozdaki başarısızlığı göstermektedir (Di Bartolomeo ve ark. 2010). Memelilerde otofaji, döllenmeden sonra ubikitin-proteazom sistemi ile birlikte sperm mitokondrisini ortadan kaldırır ve böylece heteroplazmiye katkıda bulunur (Song ve ark. 2016). İki hücreli geç evreden sonra otofaji, zigotik genom aktivasyonu için gerekli olabilecek maternal mRNA ve proteinleri hedef alarak, yüksek aktivite gösterir (Stitzel ve Seydoux, 2007 ). Otofaji, ayrıca pre-implantasyon embriyo gelişimi, hücre farklılaşması ve organogenez için hayati önem taşımaktadır (Di Bartolomeo ve ark. 2010). Eritropoez de otofaji için bir örnektir. Eritroblastlardan üretilen olgun eritrositlerde hücre fonksiyonu için gerekli olmayan mitokondri, ribozom ve diğer organellerin eliminasyonu otofajiyle sağlanır. (Mortensen ve ark, 2010). 
Yapılan çalışmalar bazı tümörlerin otofajiye bağımlı olduğunu göstermiştir (Russell ve ark. 2014). Kanserin belirlenmesinden sonraki aşamalarda, otofaji süreci metabolik stres (hipoksi, kemoterapi ve radyoterapi gibi terapötik stresler) altında tümörlerin hayatta kalmasına yardımcı olmaktadır (Ozpolat, 2015). Tümör hücreleri otofajinin geri dönüştürme özelliğini besin kaynağı olarak da kullanmaktadır (White, 2012). Otofaji yolaklarını hedefleyen otofajik inhibitörler kanser tedavisinde yakın geçmişte kullanılmaya başlanmıştır (Chude ve Amaravadi, 2017, Shi ve ark. 2017, White, 2012). Otofajinin farklı evrelerini inhibe eden birden fazla bileşik olmasına rağmen, klinik olarak onaylanmış tek otofaji inhibitörü bir anti-sıtma etmeni klorokin (CQ)'in türevi olan hidroksiklorokin (HCQ)'dir. HCQ, lizozomal asidifikasyonu inhibe etmesinden dolayı otofagozomların yıkımını önleyebilmekte ve böylece otofajiyi baskılayabilmektedir (Pellegrini ve ark. 2014). CQ türevlerinin ayrıca anti-kanser lizotrofik ilaçlanı lizozomdan serbest bırakarak işlev gördüğü gösterilmiştir (Fu ve ark. 2014, Sui ve ark. 2013). Lizotrofik ilaçlar lizozomlar içerisinde kolayca tutulur, ancak CQ türevleri ile kombine edildiğinde, bu ilaçların lizozom tarafından tutulumu azalır ve böylece sitoplazmadaki ilaç konsantrasyonu artar (Chude ve Amaravadi, 2017, Fu ve ark. 2014, Sui ve ark. 2013). Nitekim, HCQ’un diğer ajanlarla birlikte kullanıldığında, anti-neoplastik etkileri arttırdığı belirtilmiştir (Donohue ve ark. 2013, Goldberg ve ark. 2012).

\section{Morfoloji}

Otofajinin gerçekleştiğini yansıtan en önemli morfolojik özellik, otofagozom olarak adlandırılan çift-membranlı bir vezikülün de novo oluşumudur. Bununla birlikte, bu yap1 sekestrasyon sürecinin son ürünüdür ve asıl olarak otofajinin temel fonksiyonel birimi değildir. Otofagozom öncüsü fagofor, hasarlı organeller ve istilacı patojenler gibi kargoların ayrılmasından sorumlu olan dinamik zar yapısıdır. Kaynakları neredeyse tüm hücre içi organelleri olabildiği öne sürülen fagofor, zar ilavesi ile genişler ve tamamlandıktan sonra fagofor kapanır ve tamamlanmış bir otofagozom haline gelir. Mayalarda otofagozom vakuol ile birleşir. Memelilerde, otofagozom doğrudan bir lizozom ile veya bir ara amfizom oluşturmak için önce bir geç endozom ile kaynaşabilir. Otofagozomun dış zarının lizozom ile birleşmesi veya lizozom ile birlikte amfizomun sınırlayıcı zarı otolizozomu oluşturur ve kargoları degradatif lizozomal enzimlere maruz bırakır. Parçalanma ürünleri, özellikle aminoasitler, enerji üretiminde veya biyosentetik yollar için substratlar olarak kullanılmak üzere daha sonra sitozole salıverilir (Liu, 2017). 


\section{Otofaji Mekanizması}

Otofagozomlar, 1950'lerin başlarında elektron mikroskobisi ile gözlemlense de, otofajinin moleküler mekanizması son yirmi yıl içerisinde detaylı olarak incelenebilmiştir. Moleküler mekanizma ilk olarak tomurcuklanan maya, S. cerevisiae'deki çalışmalarla tanımlanmış ve bugüne kadar 40'dan fazla otofajiye bağlı (ATG) genin bu süreçte yer aldığı tespit edilmiştir (Liu, 2017). Memeli hücreleriyle yapılan daha sonraki çalışmalar, otofajinin evrimsel olarak muhafaza edildiği fikrini destekleyen temel otofaji mekanizmasında görevli proteinlerin homologlarını ortaya çıkarmıştır (Bento ve ark. 2016). Aynı zamanda, maya homologlarından yoksun memelilerde ve $C$. elegans gibi diğer model sistemlerde tanımlanan ATG proteinlerinin sayısının artmasıyla, kompleks ökaryotlarda otofajinin daha karmaşık bir mekanizmaya ve birden fazla işleve sahip olduğu düşünülmektedir. Ayrıca, otofaji proteinlerinin çoğunluğunun kompleksler olarak işlev gördüğü gösterilmiştir (Bento ve ark. 2016).

\section{Așamaları}

Otofaji, 1- çekirdeklenme (izolasyon membranının oluşumu), 2- uzama (izolasyon membranının uzaması), 3- olgunlaşma (otofagozomun tamamlanması ve taşınması), 4birleşme (otofagozom ile lizozomun kaynaşması ve birleşimi) ve 5- parçalanma (kargoların otolizozom içinde yıkımı) aşamalarından oluşmaktadır (Shuhei ve ark. 2017) (Şekil 1). Memeli hücrelerinde besin yokluğu gibi bir uyarandan sonra, otofagozom yapımının başlaması, omegazom denilen yapının oluşumu ile ER zarında meydana gelir. Fagofor (izolasyon membranının) büyümesi, hücredeki neredeyse tüm hücre içi bölümlerden girişi gerektirir. Bu görüş, fagoforun birçok organel ile temas ettiğini gösteren morfolojik verilerle desteklenmektedir (Axe ve ark. 2008; Biazik ve ark. 2015).

Çekirdeklenme aşamasında; otofajiyi düzenleyen ve FIP200, ATG13, ATG101 ile tetramerik bir kompleks oluşturan ULK1 kompleksi, Sınıf III-PI3K kompleks I (VPS34, VPS15, ATG14, Beclin1)'i aktive ederek vezikül çekirdeğini uyarır. Fagoforun daha sonra uzatılması ve kapanması ise iki ubikitin benzeri konjugasyon sistemi (ATG5-ATG12 ve LC3) ile gerçekleşir. Fagoforun ve otofagozomların mikroskobik olarak belirlenmesinde yaygın bir belirteç olarak kullanılan LC3 (hepsi LC3 olarak anılan LC3A/B/C, GATE-16 ve GABARAP 1/2/3) ATG8 ortoloğudur (Kabeya ve ark. 2000, Nakamura ve Yoshimori, 2017). ATG komplekslerinin PAS'da (fagofor oluşum bölgesi) toplanmasıyla, PAS ER'nin proksimal 
bölgesine lokalize olur ve burada omegazom adını alır. Farklı kaynakların zarları fagoforun oluşumuna katılır (Reggiori ve Ungermann, 2017). Disk benzeri yapıda genişleyen fagoforun kendi çevresinde kapanarak otofagozom haline gelmesinde COPII kaplı veziküller rol almaktadır (Shuhei ve ark. 2017). Son çalışmalar COPII kaplı veziküllerin otofajide anahtar role sahip olduğunu ve besin açısından zengin koşullar altında COPII veziküller ER-golgi trafiğine aracılık ettiğini göstermiştir. Besin yoksunluğunda ise bu veziküller otofagozom oluşumuna katkıda bulunur. COPII kaplı Sec24'ün (vezikül içinde oluşmaya başlayan 3 kargo adaptöründen biridir) fosforilasyonu, otofagozomların miktarını düzenlemek için Sec24mATG9 etkileşimini kolaylaştırır (Wang ve ark. 2017).

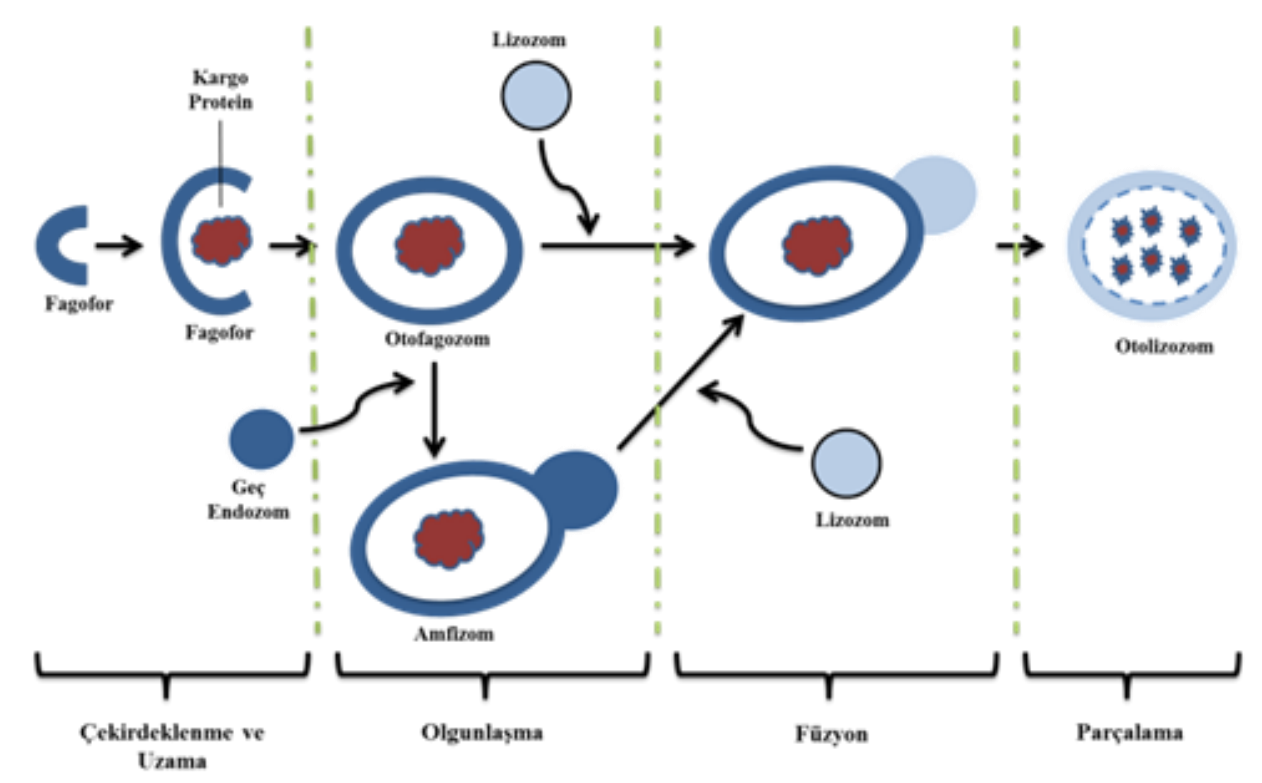

Şekil 1. Memeli hücresinde otofaji sürecinin şematik modeli. Sitosolik proteinler, protein agregatları, hasar görmüş organelleri ve istilacı patojenleri içeren yükler genişleyen ve olgunlaşarak eksiksiz bir otofagosome oluşturacak bir fagofor ile ayrılır. Otofagozomun dış zarı doğrudan lizozom zarıyla birleşebilir veya bir ara amfizom oluşturmak için önce bir geç endozom ile kaynaşabilir. Daha sonra yerleşik hidrolazlar tarafindan parçalanacak iç membranı yüklerle birlikte lizozom lümenine salıverir. Parçalanan ürünler yeniden kullanım için sitozole geri bırakılır.

Fagoforun kapanmasından sonra, ATG proteinlerinin uzaklaştırılması ile otofagozomlar olgunlaşır (Reggiori ve Ungermann, 2017). Otofagozomlar daha sonra geç endozomlarla birleşerek amfizomu veya doğrudan lizozomlarla kaynaşarak otolizozomları oluştururlar (Shuhei ve ark. 2017). Lizozomlar ve otofagozomlar arasında etkili bir birleşmenin olabilmesi için bu iki organelin perinükleer bölgeye eş zamanlı olarak taşınması 
gerekir. Açlık durumu hücre içi pH'taki değişiklikler ile lizozomların perinükleer kümelenmesine neden olurken, otofagozomlar da mikrotübüler etkileşim yoluyla hücrenin periferik bölgesine taşınır. (Reggiori ve Ungermann, 2017). Otofagozomlar lizozom ile kaynaştıktan sonra, otolizozomlarda içerikler sindirilir (Shuhei ve ark. 2017).

Birleşme sonrasında, iç vezikülün parçalanması, memeli hücrelerinde proteinaz A ve B (sırasıyla PEP4 ve PRB1 tarafından kodlanan) ve L'yi içeren bir dizi lizozomal asit hidrolaza bağlıdır (Tanida ve ark. 2005). Parçalanma sonucu elde edilen özellikle aminoasit gibi küçük moleküller, protein sentezi ve açlık koşullarında hücresel fonksiyonları korumak için sitozole geri taşınır (Yang ve ark. 2006). Otolizozomlar kalıcı yapılar değildir ve otofaji sona erdikten sonra parçalanırlar. Otofajinin sonlandırma aşaması, otofajik lizozom değişikliği (ALR) olarak adlandırılan bir işlemdir (Yu ve ark. 2010).

\section{Fagofor ve otofagozom oluşumu}

ATG protein kompleksi; ULK kinaz kompleksi, ATG12 konjugasyon sistemi, LC3 konjugasyon/dekonjugasyon sistemi, mATG9/ATG9L1 döngü sistemi ve PI3-kinaz kompleksinden oluşur (Kraft ve Martens, 2012; Lamb ve ark. 2013; Mizushima ve ark. 2011). Golgi'de bulunan ATG9 (ATG9A), golgi ile otofagozomların oluşumu arasındaki ana bağlantıyı sağlayan bir membran proteinidir. ATG9 ve ULK kompleksi, MAPK14/p38-MAP kinaz, TRAPPIII, AP2, SH3GLB1/BIF, RAB11 ve TBC1D14 tarafindan kontrol edilir (Lamb ve ark. 2016, Longatti ve ark. 2012, Mari ve ark. 2010, Webber ve ark. 2009, Yamamoto ve ark. 2012, Takahashi ve ark. 2016). ATG9A, klatrin kaplı plazma zarı bölgelerinden hücre içine alınır ve önce erken endozomlara (EE) daha sonra transferrin reseptörü ile geri dönüşüm endozomlarına (RE) iletilir. ATG16L1 ise plazma zarındaki AP2-klatrin yapılarıyla etkileşime girer (Ravikumar ve ark. 2010). Fagoforun oluşumu, ATG9 ile işaretlenmiş bir ER'in ULK kompleksi tarafından aktifleştirilmesiyle başlar. PtdIns3-kinazın toplanması ile PtdIns3P'1 içeren, omegazom olarak adlandırılan, ER domainleri oluşur (Şekil 2). Böylece protein kompleksi olan ATG12-ATG5-ATG16L1'in toplanması kolaylaşır (Davis ve ark. 2017, Dooley ve ark. 2014, Ge ve ark. 2013, Karanasios ve ark. 2016). MAM'lar (mitokondri ilişkili memranlar) veya mitokondri-ER bağlantı bölgeleri, ATG14L ve STX17 de dâhil olmak üzere ATG oluşum mekanizmasının yoğunlaştığı potansiyel alanlar olarak otofagozomların oluşumunda rol oynar (Hamasaki ve ark. 2013, Steegmaier ve ark. 1998, Tsuboyama ve ark. 2016). 


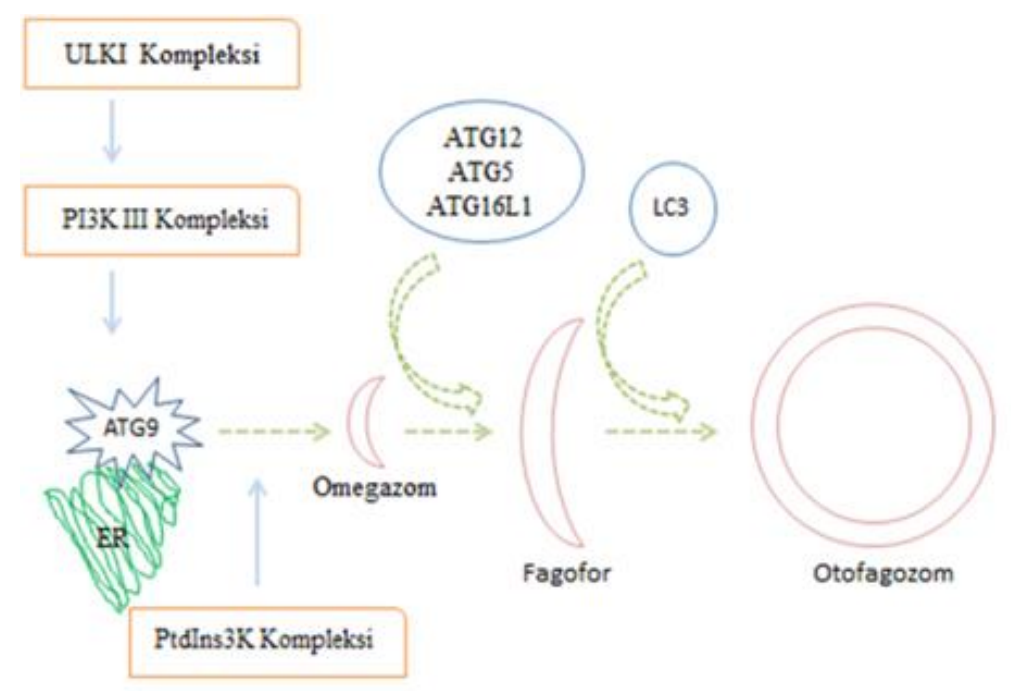

Şekil 2: Omegazom, sadece memeli hücrelerinde gözlemlenen, ER'den uzayan bir zar yapısı olup özel bir fagofor türüdür. ULK1 kompleksinin ATG9 ile işaretlenmiş ER bölgesinde fagofor oluşumu başlar. PtdIns3K'ın eklenmesiyle bu bölge omegazom olarak adlandırılır ve ATG12, ATG5 ve ATG16L1 kompleksinin toplanmasını kolaylaştırır.

Hücre içerisinde besin maddelerinin kullanılabilirliğindeki değişimi hissetmekte önemli bir rol oynayan sinyal yolaklarından birisi rapamisin kompleksi 1'dir (mTORC1). Memelilerde otofaji aktivitesini etkileyen transkripsiyon sonrası düzenlemeler mTORC1 tarafindan kontrol edilmektedir (Knaevelsrud ve ark. 2013, Moreau ve ark. 2011, Morozova ve ark. 2015, Noda, 2017, Puri ve ark. 2013). Besin yetersizliği, özellikle kısıtlı azot ve/veya aminoasit varlığında, mTORC1 uyarımını durdurarak ULK1 kompleksinin aktivasyonunu sağlayan bir hücre içi sinyal ileti zincirini başlatır (Bento ve ark. 2016, Yin ve ark. 2016). Besin yetersizliği durumunda ULK1 kompleksi diğer otofaji düzenleyici faktörlerle etkileşimini sağlayan fosforilasyon, ubikutinizasyon ve asetilasyona uğrar. Besinlerin varlığında ise ULK1, mTORC1 tarafından fosforile edilerek AMP-bağımlı protein kinazla etkileşimini kaybeder ve böylece otofaji inhibe olur (Bento ve ark. 2016). Defosforilasyonu ile otofagozom oluşumunda görev alan ATG13 ise otofajide mTORC1'in en önemli substratıdır. Memelilerde otofagozom oluşum kompleksine özgü VPS34 kompleksi tanımlanmıştır (Itakura ve ark. 2008, Kihara ve ark. 2001, Matsunaga ve ark. 2009). Bu kompleksin alt birimlerinden Beclin-1, açlık koşulları altında ULK1 tarafından fosforile edilmektedir (Russell ve ark. 2013; 2014). VPS34 kompleksinin oluşumu ile otofaji indüklenir. MTMR3 ise açlık uyarımı olmadan otofajiyi başlatan otofagozom oluşum bölgesinde artmış PI3P konsantrasyonunu arttırır. (Taguchi-Atarashi ve ark. 2010). 
MTMR3'ün doğrudan mTORC1'e bağlandığı ve mTORC1 aktivitesini baskıladığ1 bulunmuştur (Hao ve ark. 2016). Bu, açlık sinyali olmadan otofajinin neden uyarıldığını açıklayabilir.

Birleşme aşamasında SNARE protein kompleksi önemli rol oynamaktadır. Çoğunlukla ER'de bulunan bir Q-SNARE proteini olan STX17, otofagozomun kapanması sürecinde rol oynar ve birleşme mekanizmasının ana bileşenidir (Tsuboyama ve ark. 2016). Çeşitli faktörler otofagozomal SNARE kompleksini düzenler. ATG14L, STX17'ye bağlanır; ve STX17SNAP29 ikili Q-SNARE kompleksini otofagozomlar üzerinde dengeler ve membran bağını geliştirerek birleşme olaylarını arttırır (Diao ve ark. 2015, Itakura ve ark. 2012). Otofagozom ve lizozomlar, SNARE aracılı birleşme oluşmadan önce birbirine daha yakın hareket etmeli ve daha sonra bağlanmalıdır. Birleşmenin ilk basamağında, otofagozom dış membranı lizozom membranıyla birleşir. Tam birleşme ise otofagozom iç membranının lizozomal hidrolazlar tarafından sindirilmesi ve otofagozom içeriğinin lizozom lümenine maruz kalmasıyla tamamlanır (Yu ve ark. 2017). Otofagozomun oluşumu, lizozomlarla kaynaşması ve sindirilmiş içeriğin parçalanmak için başarılı bir şekilde lizozomlara ulaştırılması sıkı bir şekilde koordine edilmelidir. Bu eşgüdümlü olarak, otofagozomal SNARE olan STX17'nin lokalizasyonu kontrolü ile gerçekleştirilir (Tsuboyama ve ark. 2016).

\section{Otofagozom taşınması}

Otofagozomlar kapatıldıktan sonra, mikrotübüller aracılığıyla taşınarak lizozomların bulunduğu perinükleer bölgede yoğunlaşır. Dynein proteini otofagozomların merkeze doğru olan hareketine aracılık eder. Dyneinin işlevinin kaybı otofagozom-lizozom birleşmesinde azalmaya neden olur. Aktin esasl1 proteinler de (MIYOZIN1 ve MIYOZIN6) otofagozomlizozom birleşmesinde rol oynar (Brandstaetter ve ark. 2014, Cheng ve ark. 2015, Fass ve ark. 2006, Heuser, 1989, Jahreiss ve ark. 2008, Ravikumar ve ark. 2005, Tumbarello ve ark. 2012). Genel olarak, bağlamayı sağlayan faktörler 3 sınıfa ayrılır: HOPS kompleksi, RAB7, bağlama ve birleşme mekanizması için lizozom veya otofagozomal bileşenleri bağlayan adaptörler (Yu ve ark. 2017). HOPS kompleksi otofagozom-lizozom birleşimi için bağlama faktörüdür ve VPS11, VPS16, VPS18, VPS33A, VPS39 ve VPS41 proteinlerinden oluşur. Tüm HOPS alt birimleri otofagozom-lizozom birleşmesi için gereklidir (Rieder ve Emr, 1997, Seals ve ark. 2000, Wurmser ve ark. 2000, Takats ve ark. 2014). Otofagozomların taşınmasında RAB7, otofagozomu FYCO1 aracılığıyla bir mikrotübül motora bağlar ve hücre çevresine doğru kinesin esaslı hareketi kolaylaştırır (Şekil 3). FYCO1, LC3 ve otofagozom 
zarının bileşeni olan PI3P'ye bağlanır. Kolesterol normal seviyede iken, RAB7 ayrıca perinükleer bölgeye doğru dynein aracılı harekete katılmak için PILP ve ORP1L'ye bağlanır. Kolestrol düşük seviyede iken, ORP1L dynein alımını önleyen bir temas bölgesi oluşturur (Nakamura ve Yoshimori, 2017).

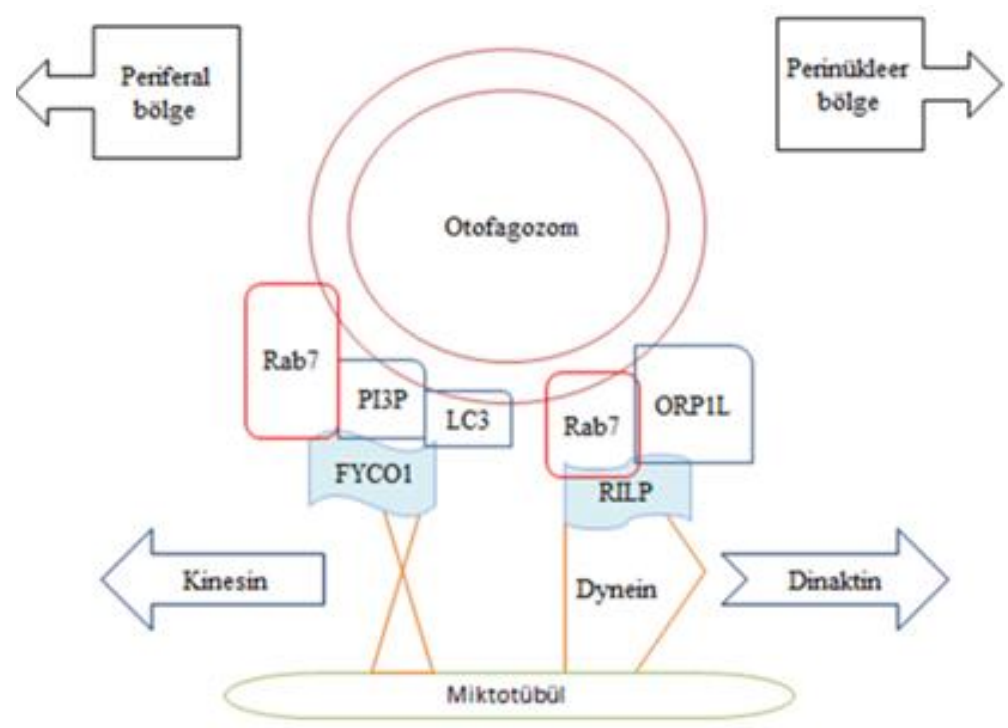

Şekil 3: Otofagozomların taşınması. RAB7 ve FYCO1 aracıllğıyla otofagozomun bir mikrotübül motora bağlanması ve hareket

\section{Sonuç}

İlk maya Atg genlerinin tanımlanmasından bu yana, otofajinin biyolojisini anlamada hızlı bir ilerleme sağlanılmış ve otofajinin insan sağlığı ve hastalıklarıyla olan ilişkisi kaydedilmiştir. Otofaji, hücrede birçok zararlı bileşeni ortadan kaldırma işlevi gördüğünden otofaji mekanizmasındaki aksamaların kanser, nörodejenerasyon, kardiyovasküler miyopati ve lizozomal depolama bozuklukları gibi çeşitli hastalıklarla ilişkili olduğu veya bu hastalıkların nedenini oluşturduğu öne sürülmüştür. Örneğin, hasarlı mitokondrinin seçici olarak parçalanması, muhtemelen oksidatif stresin azaltılması ve DNA hasarının önlenmesi yoluyla otofajinin tümör baskılayıcı etkilerinin temelinde yer aldığı düşünülmektedir. Çeşitli bulgular, otofajinin toksik agregat oluşturma eğilimli proteinlerin temizlenmesindeki rolünün Huntington, Alzheimer ve Parkinson hastalıkları gibi bazı nörodejenerasyon tiplerini önlemede kritik olduğunu ortaya koymaktadır. $\mathrm{Bu}$ nedenle, otofaji mekanizmasının 
hedeflenmesi bazı hastalıklar için uygun bir terapötik strateji olabilir. Bununla birlikte, otofajinin farklı hastalıklardaki rollerini anlamayı en üst düzeye çıkarmak için, otofaji mekanizmasının işleyişi hakkında daha fazla bilgi edinmek gereklidir.

\section{Kaynaklar}

1. Al Rawi S, Louvet-Vallee S, Djeddi A, ve ark. 2011. Postfertilization autophagy of sperm organelles prevents paternal mitochondrial DNA transmission. Science. 334: 1144-1147.

2. Anding AL, Baehrecke EH. 2017. Cleaning house: selective autophagy of organelles. Developmental Cell.41(1): 10-22.

3. Axe EL, Walker SA, Manifava M, ve ark. 2008. Autophagosome formation from membrane compartments enriched in phosphatidylinositol 3-phosphate and dynamically connected to the endoplasmic reticulum. J. Cell Biol. 182:685701.

4. Bento C, Renna M, Ghislat G, ve ark. 2016. Mammalian autophagy: how does it work? Annu. Rev. Biochem. 85: 685-713.

5. Biazik J, Yla-Anttila $P$, Vihinen $H$, ve ark. 2015. Ultrastructural relationship of the phagophore with surrounding organelles. Autophagy. 11: 439-51.

6. Brandstaetter $\mathrm{H}$, Kishi-Itakura $\mathrm{C}$, Tumbarello DA, ve ark. 2014. Loss of functional MYO1C/ myosin 1c, a motor protein involved in lipid raft trafficking, disrupts autophagosome-lysosome fusion. Autophagy. 10: 2310-23.

7. Cheng XT, Zhou B, Lin MY, ve ark. 2015. Axonal autophagosomes recruit dynein for retrograde transport through fusion with late endosomes. J. Cell Biol. 209:377-86.

8. Chude CI, Amaravadi RK. 2017. Targeting autophagy in cancer: update on clinical trials and novel inhibitors. Int. J. Mol. Sci. 18(6): 1279.

9. Davis S, Wang J, Ferro-Novick S. 2017. Crosstalk between the secretory and autophagy pathways regulates autophagosome formation. Dev. Cell. 41: 23-32.

10. Diao JJ, Liu R, Rong YG, ve ark. 2015. ATG14 promotes membrane tethering and fusion of autophagosomes to endolysosomes. Nature. 520: 563-566.

11. Di Bartolomeo S, Nazio F, Cecconi F. 2010. The role of autophagy during development in higher eukaryotes. Traffic. 11(10): 1280-1289.

12. Donohue E, Thomas A, Maurer N, ve ark. 2013. The autophagy inhibitor verteporfin moderately enhances the antitumor activity of gemcitabine in a pancreatic ductal adenocarcinoma model. J. Cancer. 4: 585-596.

13. Dooley HC, Razi M, Polson HE, ve ark. 2014. WIPI2 links LC3 conjugation with PI3P, autophagosome formation, and pathogen clearance by recruiting Atg12-5-16L1. Molecular cell. 55: 238-52.

14. Fass E, Shvets E, Degani I, ve ark. 2006.Microtubules support production of starvation-induced autophagosomes but not their targeting and fusion with lysosomes. J. Biol. Chem. 281: 36303-16.

15. Fu D, Zhou J, Zhu WS,ve ark. 2014. Imaging the intracellular distribution of tyrosine kinase inhibitors in living cells with quantitative hyperspectral stimulated Raman scattering. Nat. Chem. 6: 614-622.

16. Ge L, Melville D, Zhang M, ve ark. 2013. The ER-Golgi intermediate compartment is a key membrane source for the LC3 lipidation step of autophagosome biogenesis. eLife. 2: e00947.

17. Goldberg SB, Supko JG, Neal JW, ve ark. 2012. A phase I study of erlotinib and hydroxychloroquine in advanced non-small-cell lung cancer. J. Thorac. Oncol. 7: 1602-1608.

18. Hamasaki M, Furuta N, Matsuda A, ve ark. 2013. Autophagosomes form at ERmitochondria contact sites. Nature. 495: 389393.

MAKÜ Sag. Bil. Enst. Derg. 2017, 5(2): 205-218 
19. Hao F, Itoh $T$, Morita E, ve ark. 2016. The PtdIns3-phosphatase MTMR3 interacts with mTORC1 and suppresses its activity. FEBS Lett. 590: 161-173.

20.He C, Klionsky D. 2009. Regulation mechanisms and signaling pathways of autophagy. Annu. Rev. Genet. 43: 67-93

21. Heuser J.1989. Changes in lysosome shape and distribution correlated with changes in cytoplasmic pH. J. Cell Bio. 108: 855-64.

22. Itakura E, Kishi C, Inoue K, ve ark. 2008. Beclin 1 forms two distinct phosphatidylinositol 3-kinase complexes with mammalian Atg14 and UVRAG. Mol. Biol. Cell. 19: 5360-5372.

23. Itakura E, Kishi-Itakura C, Mizushima N. 2012. The hairpin-type tail-anchored SNARE syntaxin 17 targets to autophagosomes for fusion with endosomes/lysosomes. Cell. 151: 1256-1269.

24. Jahreiss L, Menzies FM, Rubinsztein DC. 2008. The itinerary of autophagosomes: from peripheral formation to kiss-and-run fusion with lysosomes. Traffic. 9: 574-87.

25. Johansen T, Lamark T. 2011. Selective autophagy mediated by autophagic adapter proteins. Autophagy. 7: 279-296.

26. Kabeya Y, Mizushima N, Ueno T, Yamamoto A,ve ark. 2000. LC3, a mammalian homologue of yeast Apg8p, is localized in autophagosome membranes after processing. Embo J. 19: 57205728.

27. Karanasios E, Walker SA, Okkenhaug H, ve ark. 2016. Autophagy initiation by ULK complex assembly on ER tubulovesicular regions marked by ATG9 vesicles. Nat. Commun. 7: 12420.

28. Kaur J, Debnath J. 2015. Autophagy at the crossroads of catabolism and anabolism. Nat Rev Mol Cell Biol. 16(8): 461-72.

29. Khaminets A, Behl C, Dikic I. 2016. Ubiquitindependent and independent signals in selective autophagy. Trends Cell Biol. 26(1): 6-16.

30. Kihara A, Noda T, Ishihara N, ve ark. 2001. Two distinct Vps34 phosphatidylinositol 3kinase complexes function in autophagy and carboxypeptidase Y sorting in Saccharomyces cerevisiae. J. Cell Biol. 152: 519-530.

ISSN: 2148-2837
31. Kimura T, Jia J, Claude-Taupin A, ve ark. 2017. Cellular and molecular mechanism for secretory autophagy .Autophagy. 13(6): 1084-1085.

32. Kim YC, Guan KL. 2015. Mtor: A pharmacologic target for autophagy regulation. J. Clin. Investig. 125: 25-32.

33. Knaevelsrud H, Soreng K, Raiborg C, ve ark. 2013. Membrane remodeling by the PX-BAR protein SNX18 promotes autophagosome formation. J. Cell Biol. 202: 331-349.

34. Kraft C, Kijanska M, Kalie E, ve ark. 2012. Binding of the Atg1/ULK1 kinase to the ubiquitin-like protein Atg8 regulates autophagy. EMBO J. 31: 3691-3703.

35. Kraft C, Martens S. 2012. Mechanisms and regulation of autophagosome formation. Curr. Opin. Cell Biol. 24: 496-501.

36. Lamb CA, Yoshimori T, Tooze SA. 2013. The autophagosome: origins unknown, biogenesis complex. Nat. Rev. Mol. Cell Biol. 14: 759-774.

37. Lamb CA, Nuhlen S, Judith D, ve ark. 2016. TBC1D14 regulates autophagy via the TRAPP complex and ATG9 traffic. EMBO J. 35: 281301.

38. Liu Y, Levine B. 2015. Autosis and autophagic cell death: the dark side of autophagy. Cell Death Differ. 22(3): 367-376.

39. Liu X. 2017. Molecular Mechanisms of Autophagosome-Vacuole Fusion and Degradation of Peroxisomes by Autophagy. Doktora Tezi, Michigan Üniversitesi, Moleküler, Hücresel ve Gelişimsel Biyoloji, Michigan.

40. Longatti A, Lamb CA, Razi M, ve ark. 2012. TBC1D14 regulates autophagosome formation via Rab11 and recycling endosomes. J. Cell Biol. 197: 659-75.

41. Manic G, Obrist F, Kroemer G, ve ark. 2014. Chloroquine and hydroxychloroquine for cancer therapy. Mol. Cell. Oncol. 1: e29911.

42. Marino G, Niso-Santano M, Baehrecke EH, ve ark. 2014. Self-consumption: the interplay of autophagy and apoptosis. Nat. Rev. Mol. Cell Biol. 15(2): 81-94.

MAKÜ Sag. Bil. Enst. Derg. 2017, 5(2): 205-218 
43. Mari M, Griffith J, Rieter E, ve ark. 2010. An Atg9-containing compartment that functions in the early steps of autophagosome biogenesis. J. Cell Biol. 190: 1005-22.

44. Matsunaga K, Saitoh T, Tabata K,ve ark. 2009. Two Beclin 1-binding proteins, Atg14L and Rubicon, reciprocally regulate autophagy at different stages. Nat. Cell Biol. 11: 385-396.

45. Mizushima N, Yoshimori T, Ohsumi Y. 2011. The role of Atg proteins in autophagosome formation. Annu. Rev. Cell Dev. Biol. 27: 107132.

46. Mizushima N, Komatsu M. 2011.Autophagy: renovation of cells and tissues. Cell. 147: 728741.

47. Moreau K, Ravikumar B, Renna M, ve ark. 2011. Autophagosome precursor maturation requires homotypic fusion. Cell. 146: 303-317.

48. Morozova K, Sridhar S, Zolla V, ve ark. 2015. Annexin A2 promotes phagophore assembly by enhancing Atg16L (+) vesicle biogenesis and homotypic fusion. Nat. Commun. 6: 5856.

49. Morris DH, Yip CK, Shi Y. 2015. Beclin 1Vps34 complex architecture: understanding the nuts and bolts of therapeutic targets. Front. Biol. 10: $398-426$.

50. Mortensen M, Ferguson DJ, Edelmann M,ve ark. 2010. Loss of autophagy in erythroid cells leads to defective removal of mitochondria and severe anemia in vivo. Proc. Natl. Acad. Sci. USA. 107(2): 832-837.

51. Nakamura S, Yoshimori T. 2017. New insights into autophagosome-lysosome fusion.J. Cell Sci. 1209-1216.

52. Noda T. 2017. Regulation of autophagy through TORC1 and mTORC, biomolecules. 7(3): 52.

53. Ozpolat B, Benbrook DM. 2015. Targeting autophagy in cancer management- strategies and developments. Cancer Manag. Res. 7: 291-299.

54. Pellegrini P, Strambi A, Zipoli C,ve ark. 2014. Acidic extracellular $\mathrm{pH}$ neutralizes the autophagy-inhibiting activity of chloroquine: implications for cancer therapies. Autophagy. 10: 562-571.

55. Puri C, Renna M, Bento CF, ve ark. 2013. Diverse autophagosome membrane sources

ISSN: 2148-2837 coalesce in recycling endosomes. Cell. 154: 1285-1299.

56. Ravikumar B, Acevedo-Arozena A, Imarisio S, ve ark. 2005. Dynein mutations impair autophagic clearance of aggregate-prone proteins. Nat. Genet. 37: 771-6.

57. Ravikumar B, Moreau K, Jahreiss L, ve ark. 2010. Plasma membrane contributes to the formation of pre-autophagosomal structures. Nat. Cell Biol. 12: 747-757.

58. Reggiori F, Ungermann C. 2017. Autophagosome maturation and fusion. Journal of Molecular Biology. 429(4): 486-496.

59. Rieder SE, Emr SD. 1997. A novel ring finger protein complex essential for a late step in protein transport to the yeast vacuole. Mol. Biol. Cell. 8: 2307-27.

60. Rubinsztein DC, Marino G, Kroemer G. 2011. Autophagy and aging. Cell. 146(5): 682-695.

61. Russell RC, Yuan HX, Guan KL. 2014. Autophagy regulation by nutrient signaling. Cell Res. 24: 42-57.

62. Russell RC, Tian Y, Yuan H, ve ark. 2013. ULK1 induces autophagy by phosphorylating Beclin-1 and activating VPS34 lipid kinase. Nat. Cell Biol. 15: 741-750.

63. Sato M. and Sato K. 2011. Degradation of paternal mitochondria by fertilization-triggered autophagy in C. elegans embryos. Science. 334: 1141-1144.

64. Seals DF, Eitzen G, Margolis N. 2000. A $\mathrm{Ypt} / \mathrm{Rab}$ effector complex containing the Sec1 homolog Vps33p is required for homotypic vacuole fusion. Proc. Natl. Acad. Sci. 97: 94027.

65. Shuhei Nakamura S., Tamotsu Yoshimori $T$. 2017. New insights into autophagosomelysosome fusion. J. Cell Sci. 1209-1216.

66. Shi TT, Yu XX, Yan LJ, ve ark. 2017. Research progress of hydroxychloroquine and autophagy inhibitors on cancer. Cancer Chemother. Pharmacol. 79: 287-294.

67. Song WH, Yi YJ, Sutovsky M, ve ark. 2016. Autophagy and ubiquitin-proteasome system contribute to sperm mitophagy after mammalian

MAKÜ Sag. Bil. Enst. Derg. 2017, 5(2): 205-218 
fertilization. Proc. Natl. Acad. Sci. 113(36): e526-570

68. Steegmaier M, Yang B, Yoo JS, ve ark. 1998. Three novel proteins of the Syntaxin/SNAP-25 family. Journal of Biological Chemistry. 273: 34171-9.

69. Stitzel ML, Seydoux G. 2007. Regulation of the oocyte-to-zygote transition. Science. 316(5823): 407-408.

70. Sui X, Chen R, Wang Z,ve ark. 2013. Autophagy and chemotherapy resistance: a promising therapeutic target for cancer treatment. Cell Death Dis. 4: e838.

71. Suzuki H, Osawa T, FujiokaY, ve ark. 2017. Structural biology of the core autophagy machinery, Current Opinion in Structural Biology. 43: 10-17.

72. Taguchi-Atarashi N, Hamasaki M, Matsunaga K, ve ark. 2010. Modulation of local PtdIns3P levels by the PI phosphatase MTMR3 regulates constitutive autophagy. Traffic. 11: 468-478.

73. Takats S, Nagy P, Varga A, ve ark. 2013. Autophagosomal Syntaxin17-dependent lysosomal degradation maintains neuronal function in Drosophila. J. Cell Biol. 201: 531539.

74. Takats S, Pircs K, Nagy P, ve ark. 2014. Interaction of the HOPS complex with Syntaxin 17 mediates autophagosome clearance in Drosophila.Mol. Biol. Cell. 25: 1338 - 54

75. Takahashi Y, Tsotakos N, Liu Y, ve ark. 2016. The Bif-1-Dynamin 2 membrane fission machinery regulates Atg9-containing vesicle generation at the Rab11-positive reservoirs. Oncotarget. 7(15): 20855-68

76. Tanida I, Minematsu-Ikeguchi N, Ueno T, ve ark. 2005. Lysosomal turnover, but not a cellular level, of endogenous LC3 is a marker for autophagy. Autophagy. 1: 84-91.

77. Tsuboyama K, Koyama-Honda I, Sakamaki Y, ve ark. 2016. The ATG conjugation systems are important for degradation of the inner autophagosomal membrane. Science. 354: 1036-41.

78. Tumbarello DA, Waxse BJ, Arden SD, ve ark. 2012. Autophagy receptors link myosin VI to autophagosomes to mediate Tom1-dependent

ISSN: 2148-2837 autophagosome maturation and fusion with the lysosome. Nat. Cell Biol. 14: 1024-35.

79. Yamamoto H, Kakuta S, Watanabe TM, ve ark. 2012. Atg9 vesicles are an important membrane source during early steps of autophagosome formation. J. Cell Biol. 198: 219-33.

80. Yang Z, Huang J, Geng J, ve ark. 2006. Atg22 recycles amino acids to link the degradative and recycling functions of autophagy. Mol. Biol. Cell. 17: 5094-104.

81. Yin Z, Pascual C, Klionsky DJ. 2016. Autophagy: machinery and regulation. Microb. Cell.Dec 5: 3(12): 588-596.

82. Yoshida GJ. 2017. Therapeutic strategies of drug repositioning targeting autophagy to induce cancer cell death: from pathophysiology to treatment. J. Hematol. Oncol. 10: 67.

83. Yu L, Chen Y, Tooze SA. 2017. Autophagy pathway: cellular and molecular mechanisms. Autophagy. Received 15 May.

84. Yu L, McPhee CK, Zheng L, ve ark. 2010. Termination of autophagy and reformation of lysosomes regulated by mTOR. Nature. 465: 942-6.

85. Wang Y, Peng RQ, Li DD, ve ark. 2011. Chloroquine enhances the cytotoxicity of topotecan by inhibiting autophagy in lung cancer cells. Chin. J. Cancer. 30: 690-700.

86. White E. 2012. Deconvoluting the contextdependent role for autophagy in cancer. Nat. Rev. Cancer. 12: 401-410.

87. Wurmser AE, Sato TK, Emr SD. 2000. New component of the vacuolar class $\mathrm{C}-\mathrm{V}$ ps complex couples nucleotide exchange on the Ypt7 GTPase to SNARE-dependent docking and fusion. J. Cell Biol. 151: 551-62.

88. Wang J, Davis S, Zhu M, ve ark. 2017. Autophagosome formation: Where the secretory and autophagy pathways meet. Autophagy. 13(5): 973-974

89. Webber JL, Tooze SA. 2009. Coordinated regulation of autophagy by p38alpha MAPK through mAtg9 and p38IP. EMBO J. 29: 27-40. 